\title{
Financial Security Analysis of E-Commerce Platform Based on Supply Chain for Heterogeneous Network Location Verification
}

\author{
Qiao Qu $\mathbb{D}^{1}{ }^{1}$ Cheng Liu, ${ }^{1}$ and Xinzhong Bao $\mathbb{D}^{2}$ \\ ${ }^{1}$ School of Economics and Management, University of Science and Technology Beijing, Beijing 100083, China \\ ${ }^{2}$ School of Management, Beijing Union University, Beijing 100101, China \\ Correspondence should be addressed to Qiao Qu; qq0069aa@163.com
}

Received 29 August 2021; Revised 14 November 2021; Accepted 17 November 2021; Published 13 December 2021

Academic Editor: Kashif Naseer

Copyright (c) 2021 Qiao Qu et al. This is an open access article distributed under the Creative Commons Attribution License, which permits unrestricted use, distribution, and reproduction in any medium, provided the original work is properly cited.

\begin{abstract}
The development of supply chain finance, its pricing strategy for bilateral business cooperation between e-commerce, banking institutions, and fourth-party logistics services providers has gained the attention of researchers. This paper combines the heterogeneous network location verification technology, starting from information asymmetry and Rubens bargaining game ideas, and combines it with game theory methods to provide a reference for bilateral cooperation decision-making on ecommerce platforms. The experiment results indicated the pricing decisions of e-commerce platforms which are affected by the efforts of the other party and the ability of bargaining. The quoted price increases with the decrease of the bank's ability and the increase of the service provider's ability. The pricing decisions of banks and service providers are only affected by the direct proportion of their respective business costs. When considering the introduction of incentive mechanism conditions, it is found that appropriate incentive conditions can increase the quotation of the e-commerce platform. The price quoted by the e-commerce platform that chooses to bargain with the bank is higher than the price quoted by the bank after negotiating with the service provider, which will help to better realize the benefits. Finally, the paper numerically analyzes the results of the bargaining game between e-commerce platforms and banks and fourth-party logistics service providers, and the numerical results verify the better performance.
\end{abstract}

\section{Introduction}

In recent years, with the rapid development of Information and Communication Technologies (ICTs), Internet of Things (IoTs), new retail, and digital finance, the supply chain finance model has been innovated. This strategy helps further to ease the financing difficulties and financial pressures in small and medium-sized enterprises [1]. The collaborative development model of e-commerce platforms, finance, and logistics systems has gradually emerged. The main links of the supply chain operation are completed online and promote the circulation of data information and resources between different enterprise entities. The multiagent collaboration platform-based supply chain finance has gradually become a development trend. At the same time, e-commerce platforms play an increasingly important role in the operation of supply chain finance and promote the optimal allocation of online and offline resources and information sharing. This development trend towards multiplatform cooperation has gained the interest. Business cooperation channels continue to expand $[2,3]$. However, the development of supply chain finance has been still faced challenges and has certain operational and cooperation risks. The problems of cooperative relations and benefit distribution among multiple entities have become more complicated, and related business cooperation pricing issues are worthy and need further discussion and research [4]. Since banks and fourth-party logistics service providers are, respectively, the main funders and logistics service providers for the online operation of supply chain finance. It is important to coordinate the cooperative pricing relationship between the e-commerce platform and the two parties to improve online resource circulation and business efficiency.

In the context of the gradual development of e-commerce, the government encourages the innovation of supply chain financial models that coordinate the development of e- 
commerce platforms with banks and logistics service providers. The relevant analysis of the cooperative pricing strategy of e-commerce platforms helps to reduce the cooperation crisis of participants and increase economic benefits $[5,6]$. At present, many scholars have carried out research on relevant aspects of supply chain finance, and their main content is concentrated on model development and operation, online, and offline risk management issues but there are few studies on bilateral cooperation pricing of e-commerce platforms. First of all, in the research on the development of the supply chain finance model, authors in [7] showed that the supply chain finance network structure shows the characteristics of platform and network, which promotes the information sharing and the improvement of the credit quality of small and medium-sized enterprises. Authors believed that the e-commerce environment provides opportunities for banks and financial institutions for innovate using technology and business practices [8]. Authors in [9] discussed that the logistics service providers in the supply chain can help to improve the organizational efficiency of enterprises and the level of supply chain management.

In [10], the authors found that the improvement of supply chain management has a positive impact on banks' participation in supply chain finance, the establishment of bank credit mechanisms, and risk management. Authors in [11] pointed out that the development of digital credit has the advantage of reducing transaction costs. Second, a reasonable pricing strategy will help to achieve multiplatform cooperation in the supply chain to effectively improve the efficiency of supply chain operations and corporate financing efficiency and promote the further extension of the supply chain industry chain. The authors in [12] used system dynamics to improve the supply chain of product distribution systems. The authors in [13] used the analytic hierarchy process and fuzzy set theory to study the supply chain performance and strategy issues of the purchasing department. By introducing contracts to coordinate the supply chain with capital constraints, the total benefits under centralized decision-making can be realized, and the overall efficiency of the supply chain and the cooperation and win-win of the main body can be improved. At the same time, game theory research methods have been well used, including the study of the profit distribution game model of upstream and downstream enterprises in the supply chain $[14,15]$. Use the optimized game model to study corporate financing operation decisions and build a Stackelberg game model to discuss the collaborative innovation of supply chain companies $[16,17]$.

This paper combines the heterogeneous network location verification technology and draws the idea of dynamic bargaining game to analyze the bilateral pricing strategy of e-commerce platforms. To sum up, although the existing literature studies mostly focused on the traditional supply chain finance model and its development, supply chain financing and risk issues, and product distribution strategies and discussed the cooperation model of the participants and the platform distribution channels. But still, from the perspective of e-commerce platforms, it is rare to use bilateral bargaining models to analyze the pricing issues of cooperating with banking institutions and service providers at the same time. Based on this, the main contribution of the paper is combining the heterogeneous network location verification technology, drawing on the idea of dynamic bargaining game, and analyzing the bilateral pricing strategy of ecommerce platforms.

The structure of the paper is organized as follows: Section 1 presents the model description and model assumptions, explaining the brief process of parameter setting and bargaining on the e-commerce platform. Section 2 discusses the game model of bargaining with fourth-party service providers and banking institutions and analyzes the results of the e-commerce platform. Section 3 illustrates the numerical analysis, combining the research results to analyze the influence of relevant factors on the pricing decisions of the partners. Section 4 presents the conclusion, which puts forward the deficiencies and prospects of the research in this paper, and tries to make relevant suggestions based on the conclusion.

\section{Model Description and Model Assumptions}

\subsection{Heterogeneous Network Location Verification. The loca-} tion management technology of heterogeneous networks is one of the research area. There are various studies that discussed the location management technology for heterogeneous wireless networks, including link layer location management technology, network layer location management technology, and application layer location management technology [18]. In the network architecture of wide local area network (WLAN) and mobile communication network interconnection, 3Gpp and 3GppZ both decided to adopt the mobile Internet Protocol (IP) proposed by Internet Engineering Task Force (IETF) to realize the location management of WLAN terminal $[19,20]$. However, the mobile communication network itself has a very mature mechanism for location management, and the network architecture of the mobile communication network is constantly evolving. In this case, how to use the mobile IP protocol to realize the location management function of WLAN and mobile communication network interconnection still needs a lot of research work [21-23]. However, in the HMIPv6 mobility architecture, all packets sent by the communication peer to all mobile nodes (MNs) in the anchor area network and must pass through a fixed MAP. The MAP receives all the data packets on behalf of the mobile terminal it serves and encapsulates these data packets and forward to the current address of the terminal [24, 25]. Therefore, MAP consumes a lot of processing power in route search and packet forwarding, which seriously affect the overall performance of the network. The performance of MAP becomes a bottleneck for the entire network. In the future heterogeneous and convergent network environment, existing wireless access technologies are evolving with an advanced stage, new wireless access technologies continue to emerge, and they complement each other to form a network with overlapping coverage. Figure 1 reflects the 


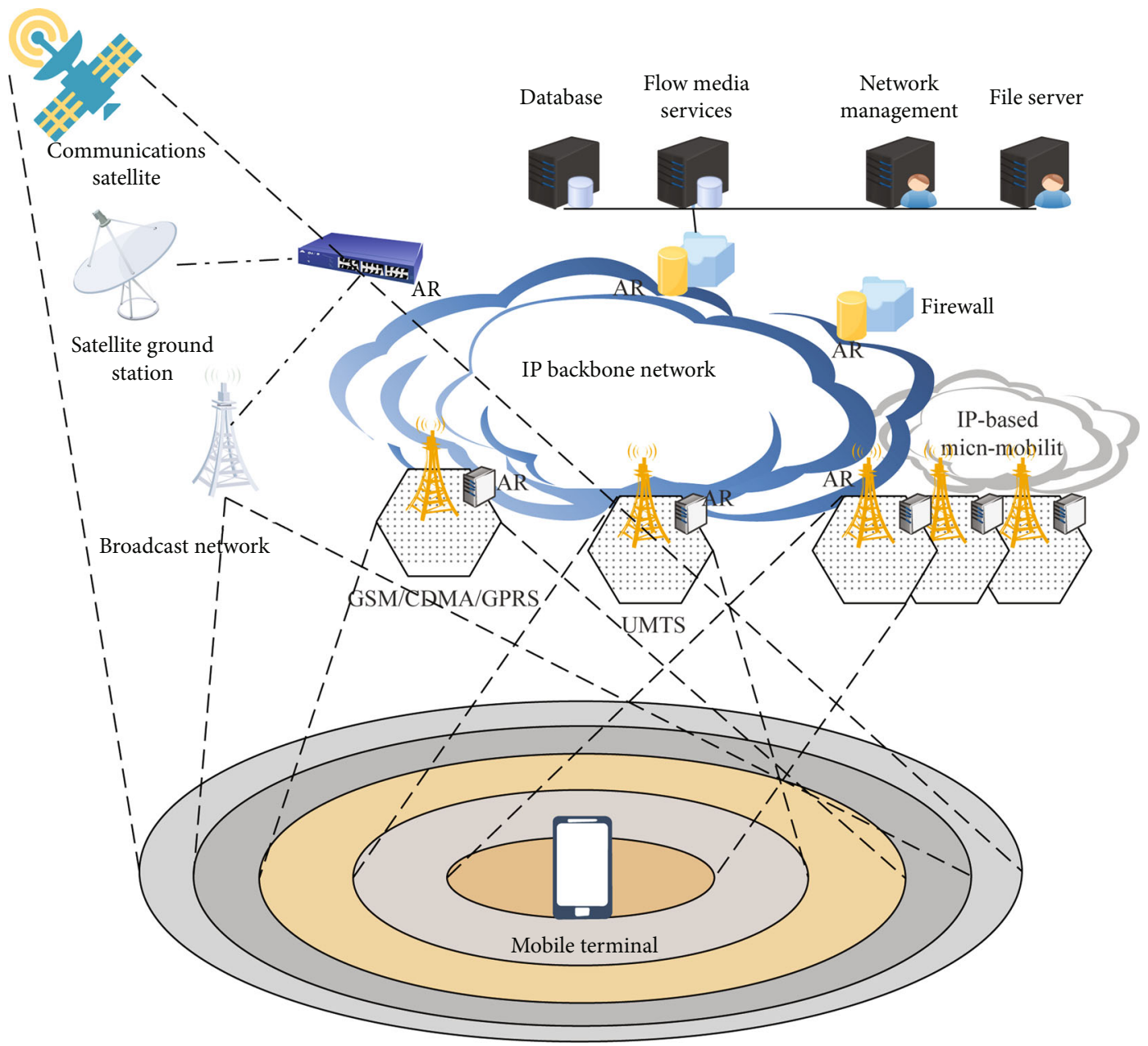

FIGURE 1: Future heterogeneous converged network environment.

schematic diagram of the future heterogeneous converged network environment.

From the current technology perspective, mobile IPbased network layer mobility management is adopted for terminal roaming in a heterogeneous network environment, which can better shield various lower-layer wireless communication technologies and realize seamless user roaming and unified mobility management to achieve the ultimate goal of personal communication [26]. For the movement within the anchor domain, the MN only moves between subnets, and the MAP to which the MN belongs before and after the movement does not change. For the movement between the anchor domains, the MAP that the MN belongs to before and after the movement changes, but the MAP before and after the movement still belongs to the same access network and is controlled by the same CMAP (Or HA) management [27]. For the movement between visiting networks, the MAPs before and after the MN moves are in different visits and are managed by different CMAPs.

\subsection{E-Commerce Platform Supply Chain Model Description.} This paper is based on the important position of ecommerce platform in the supply chain financial business, and it is playing an increasingly important role in the multi- platform cooperation model. Based on the e-commerce platform undertaking the credit entrusted business of banking institutions and the logistics integrated service business outsourcing to the fourth-party logistics service provider, this paper establishes the bilateral bargaining model of the ecommerce platform in business cooperation and discusses the different bargaining orders. That is, the platform first bargained with service providers, and then with the banking institutions bargaining strategy, and the platform first bargained with banking institutions, and then bargaining strategies with service providers, and based on the relevant conclusions drawn, consider the introduction of incentive mechanism conditions for analysis. This will not only help banks expand their customer base and business channels but also promote fourth-party service providers to further build a comprehensive service system that integrates warehousing and transportation, circulation processing, technical consultation, and resource integration. The brief schematic flow of bilateral bargaining on the e-commerce platform can be represented in Figure 2.

Using the bargaining game method, we can simulate and solve the real transaction and interest coordination issues through negotiation between the two parties. For the party undertaking bilateral bargaining, the reasonable pricing 


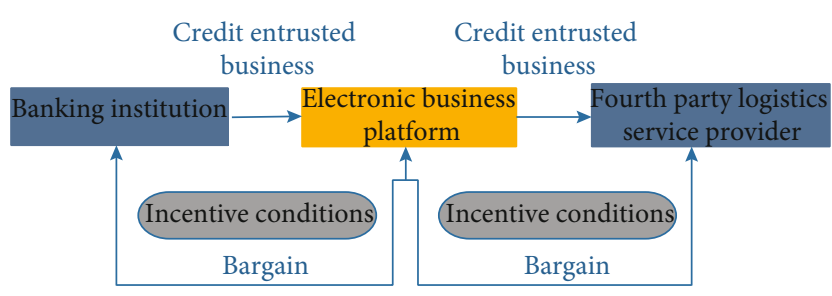

FIGURE 2: Schematic diagram of bilateral bargaining on ecommerce platforms.

issues discussed are also affected by the game decisions of other parties. From the perspective of revenue, e-commerce platforms play an important role in information sharing and resource integration, building a bridge for cooperation between multiple platforms in supply chain finance. When establishing the game model, this paper considers that the platform revenue is mainly derived from the pricing income of the bank's credit entrustment business and deducts the pricing expenses of the product logistics service business with the fourth-party service provider. In addition, it does not consider the business cooperation to the parties. The related hidden income is brought by it, such as the trust and satisfaction of the client enterprise, the stickiness and intensity of cooperation between the parties and the bank, the improvement of platform information management level, the improvement of transportation logistics, and product quality service system.

\subsection{Model Assumptions and Parameter Description}

Hypothesis 1. E-commerce platforms, banks, and fourthparty service providers have the ability to learn in the game and can make decisions and anticipate adjustments based on the behavior of another game party. The pricing and cooperation plans reached by the parties in the bargaining game are mainly affected by factors such as their respective business costs, effort level, affordability, bargaining ability, and order.

Hypothesis 2. E-commerce platforms can obtain certain benefits from participating in cooperation and promote the circulation and sharing of information resources in the supply chain. In addition, in the information age, banks gradually give way to the e-commerce platform and the fourth party in cooperation. Here, $C_{b}$ can be used to indicate that the bank alone bears the cost of the business, including the collection and review of customer enterprise credit information, product pledge, and supervision [28]. Let $C_{e}$ denote the final business price reached between the e-commerce platform and the bank. If the incentive mechanism is considered, the bank sets incentive coefficients $\alpha \alpha \geq 1$ for the ecommerce platform, that is, $\alpha C_{e}$ is used to represent the bank's subsidies and sharing of costs such as technical input and information management when developing business on the e-commerce platform, which can also mobilize electricity. The investment enthusiasm and effort level of the business platform can obtain hidden benefits. At the same time, by setting an incentive factor $T$, it means the amount of penalties imposed by banks on e-commerce platforms withdrawing from cooperation or business violations, in order to deal with online operations and moral hazards that may be involved in e-commerce platforms, or to seek better partners and withdraw from the constraints of the cooperation [29].

Hypothesis 3. In cooperation with fourth-party service providers, e-commerce platforms can not only use the advantages of service providers in product pledge, circulation processing, quality and safety, technical consultation, and resource integration, to entrust enterprise product circulation services. Here, $C_{f}$ is used to represent the business cost of the fourth party service provider. Let $C_{s}$ denote the final business price reached between the e-commerce platform and the fourth-party service provider. If the incentive mechanism is considered, the e-commerce platform has an incentive coefficient $\beta, \beta \geq 1$ for the fourth-party service provider, that is, $\beta C$ is used to represent the subsidy of the ecommerce platform to the service provider's business cost or the reward in the supervision process, which can also promote service providers actively promote business processes and improve logistics management to obtain hidden benefits; at the same time, by setting up incentive factors, it means that the e-commerce platform imposes penalties on fourth-party service providers' withdrawal from cooperation or business violations to provide services The business risks and issues that may be involved in the cooperation are constrained.

Hypothesis 4. Each party in the game can estimate the cost of benefits of other parties based on experience. Therefore, it is assumed that the e-commerce platform can estimate $C_{b}, C_{f}$ according to experience. All follow the uniform distribution of $F$. The bank estimates that $F$ obeys the uniform distribution of $[m, n]$. Fourth, the service provider estimates that $C_{s}$ obeys the uniform distribution of $[m, n]$. If there is $C_{b} \geq C_{e}$ $\geq C_{s}$, the intermediate business transaction will be reached, and vice versa.

Hypothesis 5. Taking $\lambda_{e}, \lambda_{b}, \lambda_{f}$ as the discount factor for ecommerce platforms, banks, and fourth-party service providers, respectively, it can be regarded as the degree of cooperation and bargaining power of all parties in the game process, and $0<\lambda_{e}, \lambda_{b}, \lambda_{f}<1$ mainly refers to the fact that all parties are if the cooperation agreement is reached late, the price will be paid, otherwise, the parties will tend to reach the cooperation late [30].

Hypothesis 6. In terms of revenue, the revenue of the ecommerce platform mainly comes from the pricing revenue of the bank and the difference between the pricing expenditure of the fourth-party service provider, and other hidden benefits and other costs are not considered here. When choosing a strategy, when the e-commerce platform chooses to bargain with the bank first, the quoted price is represented by $P_{e i}(i=1,3,5 \cdots)$, and $P_{b j}(j=2,4,6 \cdots)$ is the quoted price when the bank is playing with the e-commerce platform. At this time, if the price quoted by the e-commerce 
platform is higher than the bank's expectations estimate that the bank may choose not to cooperate and complete the business on its own. Then, the e-commerce platform then bargained with the fourth-party service provider's quotation is represented by $P_{s i}(i=1,3,5 \cdots), P_{f j}(j=2,4,6 \cdots)$ is the quotation provided by the fourth-party service provider in the game with the e-commerce platform, if the ecommerce platform first communicates with the bank, the price offered is low, and it may have a weaker advantage when bargaining with service providers. The paper mainly analyzes the two-stage game model of the parties to the game, regardless of the situation of the financing company. The symbols and meanings of the relevant parameters can be seen in Table 1 .

\section{Model Establishment and Analysis}

(a) The e-commerce platform first negotiates with the fourth-party logistics service provider

In this strategy, if the two parties first reach a deal, it is equivalent to that the e-commerce platform can have relative psychological expectations and estimates when it knows its own cost function and then bargain with the bank, which can guarantee better returns; on the contrary, if the two parties do not reach a deal, the game ends.

(b) The game between e-commerce platforms and fourth-party logistics service providers

In the first stage of the game, if the fourth-party logistics service provider does not accept the offer from the ecommerce platform, the two parties enter the second stage of the game and the service provider will make an offer. Use the reverse induction method to solve, first discuss the second stage of the game [31]. If the quotation $P_{f 2}$ provided by the service provider satisfies the condition that the income of the e-commerce platform is positive, that is, $\lambda_{e}$ ( $\left.C_{e}-P_{f 2}\right) q \geq 0, C_{e} \geq P_{f 2}$, where $q$ is the workload of the two parties to undertake the business, the e-commerce platform will accept the quotation and the game process ends. Therefore, the service provider can use condition $C_{e} \geq P_{f 2}$ as the criterion for judging whether the e-commerce platform chooses to accept, and modify the estimate that $C_{e}$ is a uniform distribution in the $P_{s 1}, n$ interval. If $\pi_{f}$ is used to represent the service provider's own income, $P_{e a}, P_{e r}$ is the ecommerce platform's choice to accept and reject the probability of quotation, then:

$$
\begin{gathered}
\max _{f 2}^{\max } \pi=0 P_{e r}+\lambda_{f}\left(P_{f 2}-C f\right) q P_{e a}, \\
P_{e a}=P\left(C_{e} \geq P_{f 2}\right)=\frac{n-P_{f 2}}{n-P_{s 1}}, \\
P_{e r}=P\left(C_{e}<P_{f 2}\right)=\frac{P_{f 2}-P_{s 1}}{n-P_{s 1}} .
\end{gathered}
$$

Substituting formulas (2) and (3) into formula (1), the maximum profit that the service provider can guarantee can be found, the two sides of the obtained formula are derived from $P_{f 2}$, and the service provider's quotation in the second stage of the game can be obtained as

$$
\begin{gathered}
\max _{P_{f 2}} \pi_{f}={ }_{P_{f 2}}\left[\lambda_{f}\left(P_{f 2}-C_{f}\right) q \frac{n-P_{f 2}}{n-P_{s 1}}\right], \\
P_{f 2}=\frac{\left(n+C_{f}\right)}{2} .
\end{gathered}
$$

If the e-commerce platform chooses to accept, the ecommerce platform and the service provider will obtain the following benefits:

$$
\begin{aligned}
& \lambda_{f}\left(P_{f 2}-C_{f}\right) q=\lambda_{f} \frac{\left(n-C_{f}\right) q}{2}, \\
& \lambda_{e}\left(C_{e}-P_{f 2}\right) q=\lambda_{e} \frac{\left(2 C_{e}-n-C_{f}\right) q}{2} .
\end{aligned}
$$

When looking at the first stage of the game between the two parties and the e-commerce platform proposes a quotation $P_{s 1}$, the service provider obtains revenue $\left(P_{s 1}-C_{f}\right) q$. In order to satisfy the higher revenue obtained by the service provider at this stage, it should be at $P_{s 1}$, that is, $\left(P_{s 1}-C_{f}\right)$ $q \geq \lambda_{f}\left(n-C_{f}\right) q / 2$. The service provider will tend to choose accept [32]. If $E$ is used to represent the revenue $\pi_{e}$ of the e-commerce platform, and $P_{f a}, P_{f r a}$ is the probability that the service provider chooses to accept the quotation in the first stage and the second stage, respectively, then,

$$
\begin{gathered}
\max _{P_{s 1}}^{\max } \pi_{e}=\left(C_{e}-P_{s 1}\right) q P_{f a}+\left[\lambda_{e}\left(2 C_{e}-n-C_{f}\right) \frac{q}{2}\right] P_{f r a} \\
P_{f a}=P\left(C_{f} \leq \frac{2 P_{s 1}-\lambda_{f} n}{2-\lambda_{f}}\right)=\frac{\left[2\left(P_{s 1}-m\right)-\lambda_{f}(n-m)\right]}{\left(2-\lambda_{f}\right)(n-m)}, \\
P_{f r a}=P\left(C_{f}>\frac{2 P_{s 1}-\lambda_{f} n}{2-\lambda_{f}}\right) P\left(C_{e} \geq P_{f 2}\right)=\frac{2\left(n-P_{f 2}\right)}{\left(2-\lambda_{f}\right)(n-m)} .
\end{gathered}
$$

Substituting equations (5) and (6) into equation (4) can find the maximum benefit that the e-commerce platform can guarantee, and deriving the two sides of the obtained formula with respect to $P_{s 1}$, we can get

$$
P_{s 1}=\frac{\left[2\left(C_{e}+m\right)+\lambda_{f}(n-m)\right]}{4} .
$$

That is, under normal circumstances, the quotation of the e-commerce platform in the first stage, the condition that is met at this time is $C_{f} \leq\left[2\left(C_{e}+m\right)-\lambda_{f}(n+m)\right] / 2(2$ $\left.-\lambda_{f}\right)$. If considering the addition of incentive factors, let the quotation be $P_{s 1}{ }^{\prime}, P_{s 1}{ }^{\prime}=\left[2\left(\alpha C_{e}-T+m\right)+\lambda_{f}(n-m)\right] /$ 4 , and the condition that is satisfied at this time is $C_{f} \leq[2$ ( 
TABLE 1: Parameter symbols and their description.

\begin{tabular}{|c|c|}
\hline Parameter & Meaning \\
\hline$C_{b}$ & Cost borne by the bank \\
\hline$C_{f}$ & Costs borne by fourth-party logistics service providers \\
\hline$C_{e}$ & E-commerce platform and bank bargaining the final price \\
\hline$a, T$ & Respectively, the bank's incentives for e-commerce platforms \\
\hline$C_{s}$ & The e-commerce platform negotiates the final price with the fourth-party logistics service provider \\
\hline$\beta, I$ & Respectively, the incentive factors of e-commerce platforms for fourth-party logistics service providers \\
\hline$\lambda_{e}, \lambda_{b}, \lambda_{f}$ & The discount factors of e-commerce platforms, banks, and fourth-party logistics service providers, respectively \\
\hline$P_{e i}(i=1,3,5 \cdots)$ & $\begin{array}{c}\text { Quotations made by the e-commerce platform in the game with the bank game with the fourth-party logistics service } \\
\text { provider } \\
\text { Quotations made by the e-commerce platform in the game with the bank }\end{array}$ \\
\hline$P_{s i}(i=1,3,5 \cdots)$ & The price quoted by the e-commerce platform during the game with the fourth-party logistics service provider \\
\hline$P_{b j}(j=2,4,6 \cdots)$ & Quotations made by banks in gaming with e-commerce platforms \\
\hline$P_{f j}(j=2,4,6 \cdots)$ & Quotations made by a fourth-party logistics service provider in a game with an e-commerce platform \\
\hline
\end{tabular}

$\left.\left.\alpha C_{e}-T+m\right)-\lambda_{f}(n+m)\right] / 2\left(2-\lambda_{f}\right)$, so considering the incentive mechanism will have a certain impact on the final price reached by the cooperation. In summary, the equilibrium solution results of the game between the two parties can be seen in Table 2 .

(c) The game between e-commerce platforms and banks

The research in this section is based on the situation that the abovementioned fourth-party logistics service providers first choose to accept the e-commerce platform quotation, that is, under condition $C_{f} \leq\left(2 P_{s 1}-\lambda_{f} n\right) /\left(2-\lambda_{f}\right)$, discuss the bargaining game between the e-commerce platform and the bank. For the same reason, refer to the above section for the solution process, and the game results can be seen in Table 2 .

Proposition 7. Combined with the above analysis, it can be seen that in the process of bilateral bargaining, e-commerce platforms need to combine the pricing decisions of fourthparty service providers and the business pricing decisions of banks to ensure profit.

Proposition 8. In the strategy of bargaining between the ecommerce platform and the fourth-party service provider, the service price of the first stage of the e-commerce platform is $P_{s l}$, and the price under the condition of considering the incentive factor is $P_{s 1}{ }^{\prime}$. The comparison can be obtained:

$$
\begin{gathered}
P_{s 1}{ }^{\prime}=\frac{\left[2\left(\alpha C_{e}-T+m\right)+\lambda_{f}(n-m)\right]}{4}, \\
P_{s 1}{ }^{\prime}-P_{s 1}=\frac{C_{e}(\alpha-1) T}{2} .
\end{gathered}
$$

And there is $\alpha \geq 1$.

Proposition 8 shows that under normal circumstances and considering incentive conditions, the cooperative pric- ing proposed by the e-commerce platform is different. Incentive factors have a certain impact on the behavioral decision-making of the e-commerce platform, and only affect the pricing reached in the first stage of the game between the two parties. If it is shown that the higher the subsidy and allocation amount between the incentive factors set by the bank for the e-commerce platform, and the higher the penalty amount, the greater the e-commerce revenue function platform will be. Under the premise of guaranteeing income, the price of the fourth-party service provider will be higher, which is conducive to increasing the service provider's business income [31]. If there is $T>C_{e}(\alpha-1)>$ 0 at $P_{s 1}{ }^{\prime}<P_{s 1}$, it means that when the amount of subsidy and sharing is lower and lower than the amount of penalty imposed, the income function of the e-commerce platform is smaller, and the cost and benefit protection considerations will restrict the provision price the service provider's business.

3.1. E-Commerce Platform First Bargaining Strategy with Banks. In this strategy, if the two parties first reach a deal, the e-commerce platform will be more cautious in bargaining because they cannot determine whether they can accept the fourth-party logistics service provider's quotation later; otherwise, if the two parties do not reach a deal, the game ends.

(a) The game between e-commerce platforms and banks

In the same way, use the reverse induction method to solve the problem, first discuss the second stage of the game and let the bank make a quotation first. If the bank's quotation $P_{b 2}$ meets the condition that the income of the ecommerce platform is positive, that is, at time $\lambda_{e}\left(P_{b 2}-C_{s}\right)$ $q \geq 0 P_{b 2} \geq C_{s}$, where $q$ is the workload of the two parties to undertake the business, the e-commerce platform will accept the quotation and the game process ends [33]. Therefore, the bank can modify the estimation that $\left[m, P_{e i}\right]$ is a uniform 
TABLE 2: Results of bargaining strategies between E-commerce platforms and service providers and banks.

\begin{tabular}{|c|c|c|c|}
\hline \multirow{4}{*}{ E-commerce platform first game with service provider } & \multirow{2}{*}{ Phase 1} & $\begin{array}{c}\text { E-commerce platform } \\
\text { quotation }\end{array}$ & $P_{s 1}=\left[2\left(C_{e}+m\right)+\lambda_{f}(n-m)\right] / 4$ \\
\hline & & To meet the conditions & $C_{f} \leq\left[2\left(C_{e}+m\right)-\lambda_{f}(n+m)\right] / 2\left(2-\lambda_{f}\right)$ \\
\hline & \multirow{2}{*}{ Phase 2} & Service provider quotation & $P_{f 2}=\left(n+C_{f}\right) / 2$ \\
\hline & & To meet the conditions & $C_{e} \geq P_{f 2}$ \\
\hline \multirow{4}{*}{ E-commerce platform and silver game again } & \multirow[t]{2}{*}{ Phase 3} & $\begin{array}{l}\text { E-commerce platform } \\
\text { quotation }\end{array}$ & $P_{e 1}=\left[\lambda_{b}(m-n)+2\left(n+C_{e}\right)\right] / 4$ \\
\hline & & To meet the conditions & $C_{b} \geq\left(2 P_{e 1}-\lambda_{b} m\right) /\left(2-\lambda_{b}\right)$ \\
\hline & \multirow{2}{*}{ Phase 4} & Bank quote & $P_{b 2}=\left(C_{b}+m\right) / 2$ \\
\hline & & To meet the conditions & $P_{b 2} \geq C_{e}$ \\
\hline
\end{tabular}

distribution in the $C_{s}$ interval. If $\pi_{b}$ is used to represent the bank's own income, and $P_{e a}, P_{e r}$ is the probability that the e-commerce platform chooses to accept and reject the offer, then

$$
\begin{gathered}
\max _{P_{b 2}}^{\max _{b}}=0 P_{e r}+\lambda_{b}\left(C_{b}-P_{b 2}\right) q P_{e a}, \\
P_{e a}=P\left(P_{b 2} \geq C_{s}\right)=\frac{P_{b 2}-m}{P_{e 1}-m}, \\
P_{e r}=P\left(P_{b 2}<C_{s}\right)=\frac{P_{e 1}-P_{b 2}}{P_{e 1}-m} .
\end{gathered}
$$

Substituting equations (8) and (9) into equation (7) can find the maximum income that the bank can guarantee, and deriving the two sides of the obtained formula, we can get the bank's quotation in the second stage of the game:

$$
P_{b 2}=\frac{\left(C_{b}+m\right)}{2}
$$

If the e-commerce platform chooses to accept, the bank and the e-commerce platform will obtain the following benefits:

$$
\begin{aligned}
& \lambda_{b}\left(C_{b}-P_{b 2}\right) q=\lambda_{b} \frac{\left(C_{b}-m\right) q}{2}, \\
& \lambda_{e}\left(P_{b 2}-C_{s}\right) q=\lambda_{e} \frac{\left(C_{b}+m-2 C_{s}\right) q}{2} .
\end{aligned}
$$

Looking at the first stage of the game between the two parties and the e-commerce platform proposes a quotation $P_{e 1}$, the bank will obtain income $\left(C_{b}-P_{e 1}\right) q$. In order to satisfy the bank's higher income at this stage, it should be at $\left(C_{b}-P_{e 1}\right) q \geq \lambda_{b}\left(C_{b}-m\right) q / 2$, that is, $C_{b} \geq$ $\left(2 P_{e 1}-\lambda_{b} m\right) /\left(2-\lambda_{b}\right)$, the bank will choose to accept. If $\pi_{e}$ is used to represent the income of the e-commerce platform itself, and $P_{b a}, P_{b r a}$ is the probability that the bank chooses to accept the quotation in the first and sec- ond stages, respectively, then,

$$
\begin{gathered}
\max _{P_{e 1}} \pi_{e}=\left(P_{e 1}-C_{s}\right) q P_{b a}+\lambda_{e} \frac{\left(C_{b}+m-2 C_{s}\right) q P_{b r a}}{2}, \\
P_{b a}=P\left(C_{b} \geq \frac{2 P_{e 1}-\lambda_{b} m}{2-\lambda_{b}}\right)=\frac{\left[2\left(n-P_{e 1}\right)+\lambda_{b}(m-n)\right]}{\left(2-\lambda_{b}\right)(n-m)}, \\
P_{b r a}=P\left(C_{b}<\frac{2 P_{e 1}-\lambda_{b} m}{2-\lambda_{b}}\right) P\left(P_{b 2} \geq C_{s}\right)=\frac{2\left(P_{b 2}-m\right)}{\left(2-\lambda_{b}\right)(n-m)} .
\end{gathered}
$$

Substituting equations (11) and (12) into equation (10) to find the maximum profit that the e-commerce platform can guarantee, and deriving the two sides of the formula to $P_{e 1}$, we can get

$$
P_{e 1}=\frac{\left[2\left(n+C_{s}\right)+\lambda_{b}(m-n)\right]}{4} .
$$

That is, in general, the quotation of the e-commerce platform in the first stage, the condition that is satisfied at this time is $C_{b} \geq\left[2\left(C_{s}+n\right)-\lambda_{b}(n+m) / 2\left(2-\lambda_{b}\right)\right]$; if the condition of adding an incentive factor is considered, the quotation is set to $P_{e 1}{ }^{\prime}, P_{e 1}{ }^{\prime}=\left[2 n+2\left(\beta C_{s}-I\right)+\lambda_{b}(m\right.$ $-n)] / 4$. The condition that is satisfied at this time is $C_{b} \geq\left[2\left(n+\beta C_{s}-I\right)-\lambda_{b}(m+n)\right] / 2\left(2-\lambda_{b}\right), \quad$ so consider the incentive The mechanism will have an impact on the final price of the cooperation. In summary, the equilibrium solution results of the game between the two parties can be seen in Table 3 .

3.1.1. The Game between E-Commerce Platforms and FourthParty Logistics Service Providers. This study is based on the abovementioned bank's acceptance of e-commerce platform quotations in the first stage of the game, that is, under condition $C_{b} \geq\left[2\left(C_{s}+n\right)-\lambda_{b}(n+m) / 2\left(2-\lambda_{b}\right)\right]$, discussing the bargaining game between the e-commerce platform and the fourth-party logistics service provider. Refer to the above section for the process. The game results can be seen in Table 3. 
TABLE 3: Results of bargaining strategies between E-commerce platforms and banks and service providers.

\begin{tabular}{|c|c|c|c|}
\hline \multirow{4}{*}{ E-commerce platform first game with banks } & \multirow{2}{*}{ Phase 1} & $\begin{array}{l}\text { E-commerce platform } \\
\text { quotation }\end{array}$ & $P_{e 1}=\left[2\left(n+C_{s}\right)+\lambda_{b}(m-n)\right] / 4$ \\
\hline & & To meet the conditions & $C_{b} \geq\left[2\left(C_{s}+n\right)-\lambda_{b}(n+m)\right] / 2\left(2-\lambda_{b}\right)$ \\
\hline & \multirow{2}{*}{ Phase 2} & Service provider quotation & $P_{b 2}=\left(C_{b}+m\right) / 2$ \\
\hline & & To meet the conditions & $P_{b 2} \geq C_{s}$ \\
\hline \multirow{4}{*}{ E-commerce platform and service provider game again } & \multirow{2}{*}{ Phase 3} & $\begin{array}{l}\text { E-commerce platform } \\
\text { quotation }\end{array}$ & $P_{s 1}=\left[2\left(C_{e}+m\right)+\lambda_{f}(n-m)\right] / 4$ \\
\hline & & To meet the conditions & $C_{f} \leq\left(2 P_{s 1}-\lambda_{f} n\right) /\left(2-\lambda_{f}\right)$ \\
\hline & \multirow{2}{*}{ Phase 4} & Bank quote & $P_{f 2}=\left(C_{f}+n\right) / 2$ \\
\hline & & To meet the conditions & $C_{e} \geq P_{f 2}$ \\
\hline
\end{tabular}

Proposition 9. In the strategy of bargaining with banks on the e-commerce platform, the first stage of the e-commerce platform's business pricing is $P_{e 1}$, and the pricing under the condition of incentive factors is $P_{e 1}{ }^{\prime}$. The comparison can be

$$
\begin{gathered}
P_{e 1}=\frac{\left[2\left(n+C_{s}\right)+\lambda_{b}(m-n)\right]}{4}, \\
P_{e 1}{ }^{\prime}=\frac{\left[2 n+2\left(\beta C_{s}-I\right)+\lambda_{b}(m-n)\right]}{4}, \\
P_{e 1}{ }^{\prime}-P_{e 1}=\frac{C_{s}(\beta-1)-I}{2} .
\end{gathered}
$$

And there is $\beta \geq 1$.

Proposition 9 indicates that no matter which strategy is chosen, the cooperative pricing proposed by the ecommerce platform will be different in general and under consideration of incentive conditions, indicating that the incentive factor has a certain impact on the behavioral decision-making of the e-commerce platform and only affects the game between the two parties. The pricing reached in the first stage has an impact. Among them, if 0 $\leq I<C_{s}(\beta-1)$, there is $P_{e 1}{ }^{\prime} \geq P_{e 1}$, indicating that the higher the amount of subsidies and rewards, and the higher the amount of penalty imposed by the e-commerce platform, the higher the cost of the e-commerce platform. The function is larger, and the constraint and punishment on the service provider are smaller. In order to protect the platform's revenue, the bank will offer a higher price. If there is $I>C_{s}$ $(\beta-1)>0$ at $P_{e 1}{ }^{\prime}<P_{e 1}$, it means that when the amount of subsidies and rewards is lower and lower than the amount of penalties levied, for the e-commerce platform, through the restraint and supervision of service providers, a certain amount of income is guaranteed, which helps to increase the enthusiasm of the e-commerce platform for cooperation and investment also reflects that it has a relatively small impact on the platform's bargaining attitude with the bank, which makes it easier for the bank to consider the decision-making problem of determining reasonable pricing from its own perspective. This also shows that the ecommerce platform in Proposition 7 needs to be considered in conjunction with bilateral bargaining links. The results of bargaining with one party and incentive factors will have an impact on the results of bargaining with the other party.

Proposition 10. Based on the above analysis, it is known that the e-commerce platform in the bilateral bargaining price proposed by the fourth-party logistics service provider and the bank are, respectively, $P_{s 1}$ and $P_{e 1}$. Taking the derivation of $\lambda_{f}$ and $\lambda_{b}$ on both sides of the formula, we can get

$$
\frac{\partial P_{s 1}}{\partial \lambda_{f}}=\frac{n-m}{4} \geq 0, \frac{\partial P_{e 1}}{\partial \lambda_{b}}=\frac{m-n}{4} \leq 0
$$

Proposition 10 shows that no matter which strategy the e-commerce platform chooses, its pricing decision is not affected by its own factors, but by the bargaining ability factors $\left(\lambda_{f}, \lambda_{b}\right)$ of the counterparty in the game. Among them, the e-commerce platform's pricing of service providers is positively correlated with the counterparty's bargaining power, and the bank's pricing is negatively correlated with the counterparty's ability factors; while the pricing decisions of the service provider and the bank are related to their respective business costs $\left(C_{f}, C_{b}\right)$. It is positively correlated.

Proposition 11. First of all, in strategy 1, it is known that $P_{\text {sl }}$ is the quotation of the e-commerce platform and the fourthparty logistics service provider, and $C_{e}$ is the final business price negotiated between the e-commerce platform and the bank. Since the e-commerce platform and the bank's quotation are $P_{e 1}$, so substituting it into the G formula to get the final price $P_{s 1}$ reached by the e-commerce platform and the service provider $P_{s 1}{ }^{\prime}$ :

$$
\begin{gathered}
P_{s 1}=\frac{\left[2\left(C_{e}+m\right)+\lambda_{f}(n-m)\right]}{4}, \\
P_{e 1}=\frac{\left[\lambda_{b}(m-n)+2\left(n+C_{e}\right)\right]}{4}, \\
P_{s 1}{ }^{\prime}=\frac{\left[(n-m)\left(2 \lambda_{f}-\lambda_{b}\right)+4 m+2\left(n+C_{e}\right)\right]}{8} .
\end{gathered}
$$

And if the e-commerce platform offers the same 
quotation to the service provider in the first stage, $C_{e}=[2 n$ $\left.-(n-m) \lambda_{b}\right] / 2$ can be obtained. It can be seen that in the second stage of the game, under condition $C_{f} \leq[(n-m)($ $\left.\left.\lambda_{f}-\lambda_{b}\right)+2(n+m)-2 \lambda_{f} n\right] / 2\left(2-\lambda_{f}\right)$, the service provider will choose to accept the quotation offered by the ecommerce platform and reach cooperation in the first stage of the game.

Similarly, in strategy two, it is known that $P_{e 1}$ is the quotation of the e-commerce platform and the bank, and $C_{s}$ is the business price reached by the bargaining between the e-commerce platform and the fourth-party logistics service provider. Substitute the quotation $P_{e 1}$ of the e-commerce platform and the service provider into the formula $P_{e 1}{ }^{\prime}$. Available business pricing finally reached between the ecommerce platform and the bank:

$$
\begin{gathered}
P_{e 1}=\frac{\left[2\left(n+C_{s}\right)+\lambda_{b}(m-n)\right]}{4}, \\
P_{s 1}=\frac{\left[2\left(C_{e}+m\right)+\lambda_{f}(n-m)\right]}{4}, \\
P_{e 1}{ }^{\prime}=\frac{\left[(n-m)\left(\lambda_{f}-2 \lambda_{b}\right)+2\left(C_{e}+m\right)+4 n\right]}{8} .
\end{gathered}
$$

And if the e-commerce platform offers the same quotation for the bank in the first stage, $C_{e}=\left[2 m+(n-m) \lambda_{f}\right] / 2$ can be obtained. From this, it can be seen that in the first stage of strategy $C_{b} \geq\left[(n-m)\left(\lambda_{f}-\lambda_{b}\right)+2(n+m)-2 \lambda_{b} m\right] /$ $2\left(2-\lambda_{b}\right)$, if the conditions are met, the bank will choose to accept and reach cooperation in the first stage of the game.

Compare the pricing of banks in different strategies by the e-commerce platform, that is, strategy one, after the ecommerce platform makes a quotation to the service provider, and then the quotation $P_{e 1}$ to the bank; and strategy two, the e-commerce platform to the service provider, the first stage the quotation of is substituted into the quotation for the first stage of the bank, and the quotation provided by the e-commerce platform to the bank first, that is, the final price $P_{e 1}{ }^{\prime}$ reached by the two parties, can be compared:

$$
\begin{gathered}
P_{e 1}=\frac{\left[(n-m)\left(\lambda_{f}-\lambda_{b}\right)+2(n+m)\right]}{4}, \\
P_{e 1}{ }^{\prime}=\frac{\left.(n-m)\left(\lambda_{f}-3 \lambda_{b}\right)+6 n+2 m\right]}{8}, \\
P_{e 1}{ }^{\prime}-P_{e 1}=\frac{\left[(n-m)\left(2-\lambda_{b}-\lambda_{f}\right)\right]}{8} .
\end{gathered}
$$

Because of $0<\lambda_{b}, \lambda_{f}<1$, so $P_{e 1}{ }^{\prime}>P_{e 1}$. In the same way, the pricing of service providers on e-commerce platforms is different in different strategies.

Proposition 11 indicates that the e-commerce platform's pricing decisions for banks and service providers need to consider the issues in bilateral pricing strategies at the same time. In different strategies, the price offered by the ecommerce platform to the game player is different. The price offered by the e-commerce platform to the bank will be higher than the price offered to the bank after the service provider. Therefore, for e-commerce platforms, in the process of participating in the cooperation, first determining the cooperative pricing with the bank will help achieve better returns.

Proposition 12. In strategy 1 , if the e-commerce platform can complete the game with the fourth-party logistics service provider and the bank in the first stage:

$$
\begin{aligned}
& C_{f} \leq \frac{\left[\left(2-\lambda_{f}\right)(n+3 m)+\lambda_{b}(m-n)\right]}{4\left(2-\lambda_{f}\right)}=r, \\
& C_{b} \geq \frac{\left[(n-m)\left(\lambda_{f}-\lambda_{b}\right)+2(n+m)-2 \lambda_{b} m\right]}{2\left(2-\lambda_{b}\right)}=k .
\end{aligned}
$$

Because of $k-r>0, C_{b} \geq C_{f}$ can be obtained; and it can be analyzed that the income of the e-commerce platform is positive, that is, the difference between the price $P_{e 1}$ of the e-commerce platform and the bank and the price $P_{s 1}{ }^{\prime}$ of the service provider is positive, where $P_{s 1}{ }^{\prime}$ is determined by substituting $P_{e 1}$ into $P_{s 1}$ to get, namely,

$$
\begin{aligned}
P_{s 1} & =\frac{\left[2\left(C_{e}+m\right)+\lambda_{f}(n-m)\right]}{4}, \\
P_{e 1} & =\frac{\left[2(n+m)+(n-m)\left(\lambda_{f}-\lambda_{b}\right)\right]}{4}, \\
P_{s 1}{ }^{\prime} & =\frac{\left[(n-m)\left(3 \lambda_{f}-\lambda_{b}\right)+2 n+6 m\right]}{8} .
\end{aligned}
$$

Because of $P_{e 1}-P_{s 1}{ }^{\prime}>0$, the income of the e-commerce platform is positive under this condition. Similarly, in the second strategy, if the e-commerce platform can complete the game with the bank and the service provider in the first stage:

$$
\begin{gathered}
C_{f} \geq \frac{\left[(n+m)\left(2-2 \lambda_{b}\right)+(n-m)\left(\lambda_{f}-\lambda_{b}\right)+4 n\right]}{4\left(2-\lambda_{b}\right)}=\varepsilon, \\
C_{f} \leq \frac{\left[(n-m)\left(\lambda_{f}-\lambda_{b}\right)+2(n+m)-2 \lambda_{f} n\right]}{2\left(2-\lambda_{f}\right)}=\mu .
\end{gathered}
$$

There may be $C_{b} \geq C_{f}$, and the e-commerce platform income may be positive.

Proposition 12 shows that if condition $C_{b} \geq k, C_{f} \leq r$, $C_{f} \leq C_{b}$ is met, the e-commerce platform can first complete the game with the service provider in one stage and then complete the game with the bank in one stage, and the return is positive. Under condition $C_{b} \geq \varepsilon C_{f} \leq \mu$, the ecommerce platform can first complete the game with the bank in one stage and then complete the game with the service provider in one stage. 
Proposition 13. In strategy 1 , if the e-commerce platform first completes the game with the fourth-party logistics service provider in the first stage, and then completes the game with the bank in the second stage, it will exist when the game process between the e-commerce platform and the bank enters the second stage condition:

$$
\begin{gathered}
P_{b 2}=\frac{\left(C_{b}+m\right)}{2} \geq \frac{\left[2 m+(n-m) \lambda_{f}\right]}{2}, \\
C_{b}<\frac{\left[(n-m)\left(\lambda_{f}-\lambda_{b}\right)+2(n+m)-2 \lambda_{b} m\right]}{2\left(2-\lambda_{b}\right)}=\omega .
\end{gathered}
$$

Therefore, there is inequality $(n-m) \lambda_{f}+m \leq C_{b}<[(n$ $\left.-m) \lambda_{f}+(n+m)\left(2-\lambda_{b}\right)\right] /\left(4-2 \lambda_{b}\right)$, and the condition $\left[\lambda_{f}\right.$ $\left.\left(3-2 \lambda_{b}\right)+\lambda_{b}\right] / 2<1$ can be established by observing both sides of the inequality. The first-stage game condition between the e-commerce platform and the service provider is $C_{f} \leq v$, combined with the condition $C_{f} \leq C_{b}$, the second inequality about $C_{b}$ can be obtained as follows:

$$
\begin{aligned}
& C_{f} \leq \frac{\left[C_{b}+3 m-\lambda_{f}(n+m)\right]}{2\left(2-\lambda_{f}\right)}=v, \\
& C_{b} \geq \frac{\left[3 m-\lambda_{f}(n+m)\right]}{\left(3-2 \lambda_{f}\right)} .
\end{aligned}
$$

After comparing the two inequalities, it is found that

$$
\frac{\left[3 m-\lambda_{f}(n+m)\right]}{\left(3-2 \lambda_{f}\right)}-\frac{\left[(n-m) \lambda_{f}+(n+m)\left(2-\lambda_{b}\right)\right]}{\left(4-2 \lambda_{b}\right)<0} .
$$

Therefore, there is an intersection between inequalities, there is $t \leq C_{b}<\left[(n-m) \lambda_{f}+(n+m)\left(2-\lambda_{b}\right)\right] /\left(4-2 \lambda_{b}\right)$, where $t=\max \left[(n-m) \lambda_{f}+m,\left[3 m-\lambda_{f}(n+m)\right] /\left(3-2 \lambda_{f}\right)\right]$

Proposition 13 shows that when condition $C_{f} \leq v, t \leq$ $C_{b}<\omega$ is met, the e-commerce platform can also choose to complete the bargaining game with the service provider in the first stage and then complete the game with the bank in the second stage.

\section{Numerical Analysis}

Combining the above analysis, the results of the bargaining game between e-commerce platforms and banks and fourth-party logistics service provider platforms are numerically analyzed. Suppose that the basic parameters are taken as $m=10, n=30, \lambda_{f}, \lambda_{b}$ is in the interval $(0,1), \alpha, \beta \geq 1, T$, $I \geq 0$. The setting of parameters needs to meet the constraints of the above propositions. Suppose that $P_{s 1}$ and $P_{s 11}{ }^{\prime}$ are used to represent the quotation of the service provider in the first stage of the game under normal circumstances and with the addition of incentive factors, respectively, and $P_{e 1}$ represents the general situation, the ecommerce platform first offers the quotation to the service provider, and then the quotation offered by the bank in the first stage of the game. $P_{b 2}$ represents the quotation offered by the bank during the second stage of the game between the e-commerce platform and the bank, and $P_{e 11}$ and $P_{e 11}{ }^{\prime}$, respectively, represent general under the circumstances and with the addition of incentive factors, the e-commerce platform first quotes the bank's quotation in the first stage. $P_{e 1}{ }^{\prime}$ indicates that considering the e-commerce platform's subsequent transaction with the service provider, the bank's first stage of the game offer.

4.1. The Impact of Incentive Factors on the Pricing Strategy of E-Commerce Platforms. When considering the inclusion of incentive factors, it will have a certain impact on the pricing behavior of the e-commerce platform. The incentive factors added by one party in the cooperation will affect the pricing decision of the other party in other cooperation. Figure 3 reflects the changes in e-commerce platform's decisionmaking for service providers under the influence of incentives.

According to the results of the numerical analysis, it can be seen from Figure 3 that if the amount of cost subsidies and sharing incentives invested by the bank on the ecommerce platform is higher than the amount of penalty incentives levied in advance for the platform cooperation crisis, when it meets $0 \leq T<C_{e}(\alpha-1)$, there is $P_{s 11}{ }^{\prime}>P_{s 1}$, that is, the e-commerce platform will increase the price of the service provider, so that the service provider can get higher cooperation rewards in the negotiation with it. In addition, the platform's offer $P_{s 11}{ }^{\prime}$ to the service provider will increase as $\alpha$ increases. Conversely, the platform's offer to service providers will decrease with the increase of. When $T>C_{e}(\alpha-1)>0$ is met and the penalty parameter is higher than the value of the subsidy parameter, the platform's offer to the service provider will be reduced. The analysis is mainly due to the decrease in the pricing income obtained by the e-commerce platform from the negotiation with the bank, and the platform is out of interest. The angle of view will reduce the cost of outsourcing by lowering the quotation of service providers. For banks, the restriction and supervision of the platform can better reduce transaction costs, mobilize the enthusiasm in the supply chain finance business, and promote the development of client enterprise financing projects on the platform. In addition, from the numerical analysis, it can be concluded that the quotation $P_{s 11}{ }^{\prime}$ of the e-commerce platform to the service provider will not be affected by the change of the $\beta$ value. Figure 4 reflects the changes in e-commerce platforms' pricing decisions for banks under the influence of incentives.

It can be seen from Figure 3 that if the amount of subsidies or business rewards invested by the e-commerce platform to the service provider is higher than the amount of penalties levied in advance, when it meets $0 \leq I<C_{s}(\beta-1)$, there is $P_{e 11}{ }^{\prime}>P_{e 11}$, that is, the e-commerce platform will propose a higher level to the bank. Quotation, which is conducive to obtaining higher cooperation rewards. In addition, the platform's offer $P_{e 11}{ }^{\prime}$ to the bank will increase as $\beta$ increases. Conversely, the quotation $P_{e 11}{ }^{\prime}$ of the platform to the bank will decrease with the increase of $I$; when $I>$ $C_{s}(\beta-1)>0$ is met and the value of the penalty parameter 


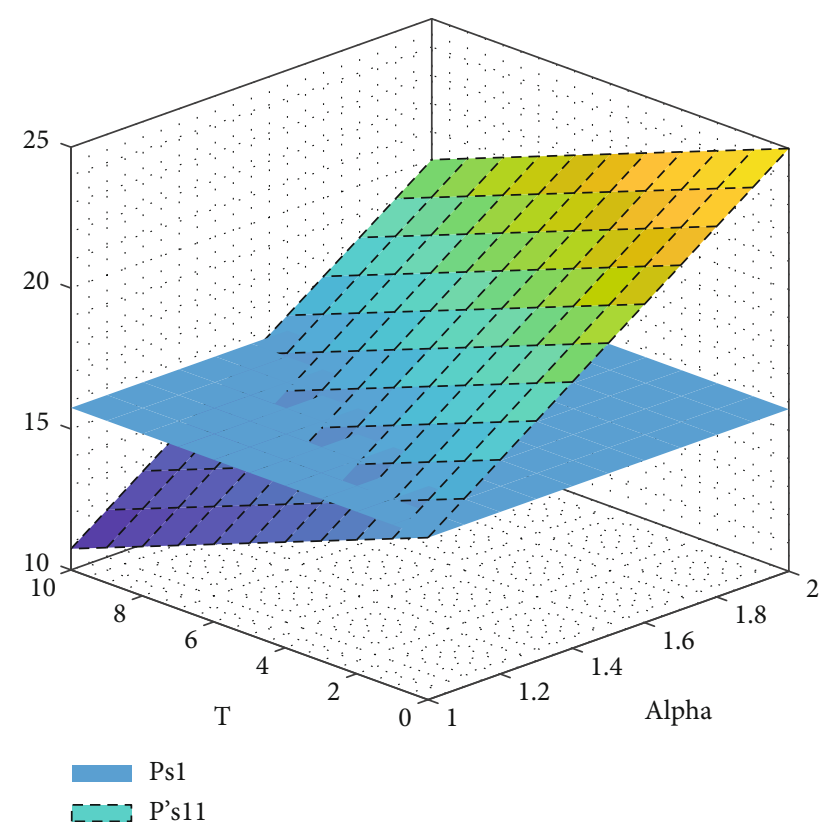

FIGURE 3: The changing trend of e-commerce platform's pricing of service providers under different incentive factors $\alpha, T$.

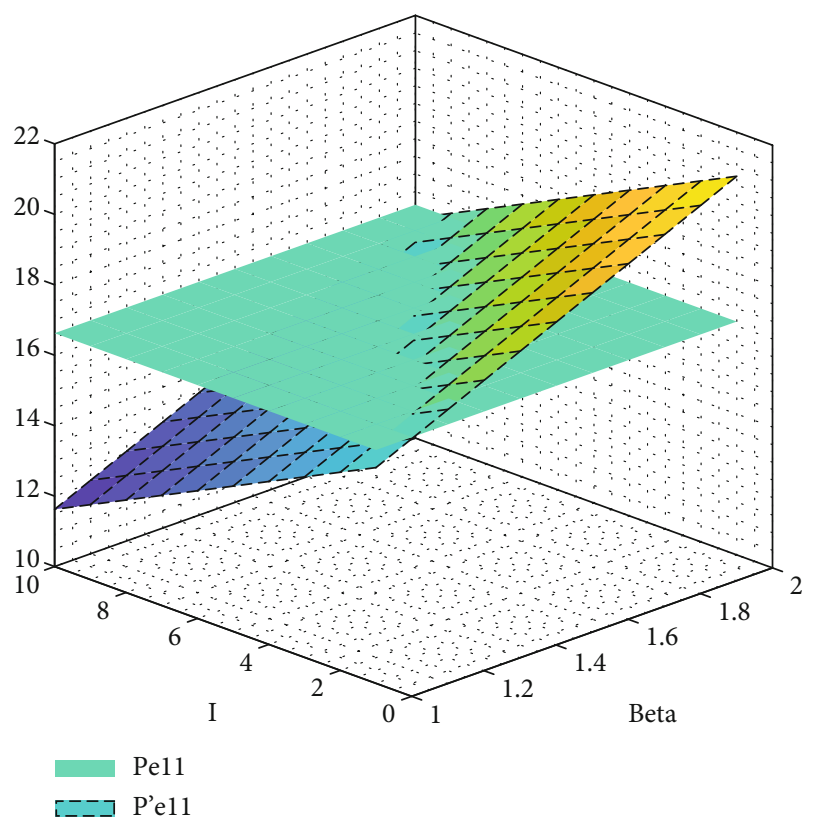

Figure 4: The changing trend of bank pricing by E-commerce platforms under different incentive factors $\beta, I$.

is higher, the quotation of the platform to the bank will decrease. The analysis is mainly because the platform can reach the service provider well. The purpose of the supervision of the business development process is to ensure that the bank's quotation is less demanding on the premise of ensuring its own benefits, which is beneficial to stimulate the bank's cooperation initiative. In addition, from the numerical analysis, it can be concluded that the e- commerce platform's offer $P_{e 11}{ }^{\prime}$ to the bank will not be affected by the change in the value of $\alpha$. Therefore, each participant can make relevant pricing decisions from the perspective of their own benefits and cooperation, which is in line with the calculation results of Propositions 8 and 9. At the same time, it also shows that e-commerce platforms need to consider decision-making in conjunction with bilateral bargaining links and make timely adjustments. The results of the bargaining game with one party and the incentive conditions will affect the results of the game with the other party, which conforms to the conclusion of Proposition 7.

4.2. The Influence of the Bargaining Power of Banks and Service Providers on the Pricing Strategy of E-Commerce Platforms. While keeping the value of $\lambda_{f}$ unchanged, observing the pricing trends of the e-commerce platform when the value of $\lambda_{b}$ is different, it can be seen that as the value of $\lambda_{b}$ continues to increase, no matter which pricing strategy the e-commerce platform chooses, the platform's trend of pricing $P_{e 1}$ will continue to decrease, which is negatively correlated with factors related to bank bargaining power. The impact on the pricing of the platform and the service provider is relatively small, that is, the change trend of $P_{s 1}$ is relatively flat. Figure 5 reflects the influence of banks' bargaining power on the pricing decisions of e-commerce platforms.

At the same time, when the platform chooses the strategy of bargaining with the service provider first and then with the bank, the ability influencing factor has less impact on the platform's pricing behavior, that is, the change trend of $B$ is relatively flat. Comply with the calculation result of Proposition 10. In addition, under different values of $P_{e 1}{ }^{\prime}$, the e-commerce platform's first offer to the bank $P_{e 1}$ will be higher than the first offer to the service provider, and then the offer to the bank $E$. Therefore, if the pricing strategy can be achieved, the platform chooses to first determine the pricing of business cooperation with the bank, which will help it obtain better returns, which is in line with the calculation results of Propositions 11 and 12. Figure 6 reflects the influence of service providers' bargaining power on the pricing decisions of e-commerce platforms.

As shown in Figure 6, while keeping the value of $\lambda_{b}$ unchanged, observing the changing trend of e-commerce platform pricing with different values of $\lambda_{f}$, it can be seen that as the value of $\lambda_{f}$ continues to increase, the platform's pricing trend for service providers will constantly rise, and it is positively correlated with the bargaining power factor of service providers.

4.3. The Impact of Bank and Service Provider Cost Factors on E-Commerce Platform Pricing Strategies. According to the analysis of Proposition 13, observe the pricing decision of the e-commerce platform under the condition of conforming to $C_{f} \leq v, l \leq C_{b}<\omega$, and the relationship $\left[\lambda_{f}\left(3-2 \lambda_{b}\right)\right.$ $\left.+\lambda_{b}\right] / 2<1$ is established. It can be seen that no matter in general or in the presence of incentive factors, the ecommerce platform can choose to first offer a quotation with the service provider, and then offer a quotation with the 


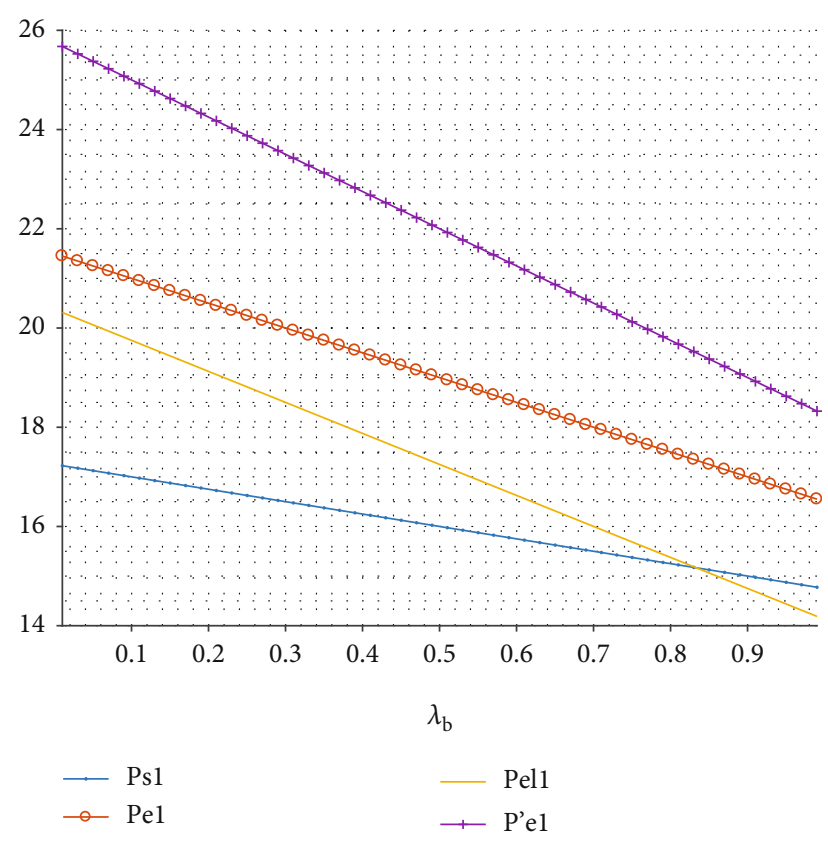

FIGURE 5: The changing trend of E-commerce platform pricing under different bargaining power $\lambda_{b}$.

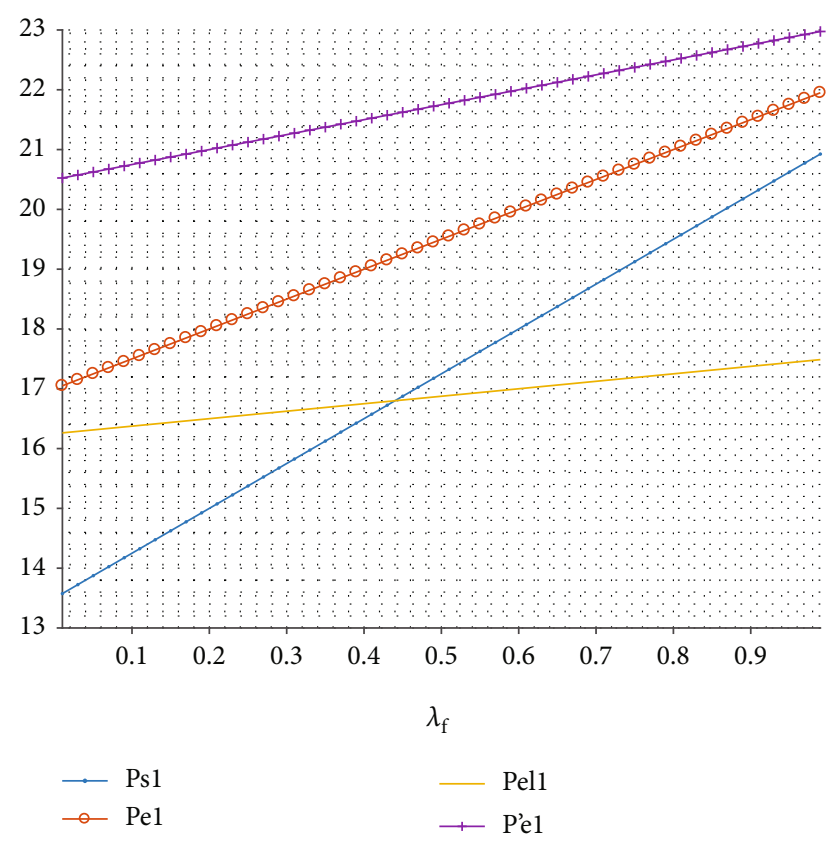

Figure 6: The pricing trends of E-commerce platforms under different bargaining power $\lambda_{f}$.

bank in a stage of the game, and the return is positive. You can also choose to accept the quotation proposed by the bank in the second-stage game with the bank and complete the transaction. At this time, it must conform to the relational formula of $\lambda_{f}, \lambda_{b}$ and the calculation result of Proposition 13. Figure 7 reflects the impact on the pricing strategy of e-commerce platforms under the conditions of changing the business costs of banks and service providers.

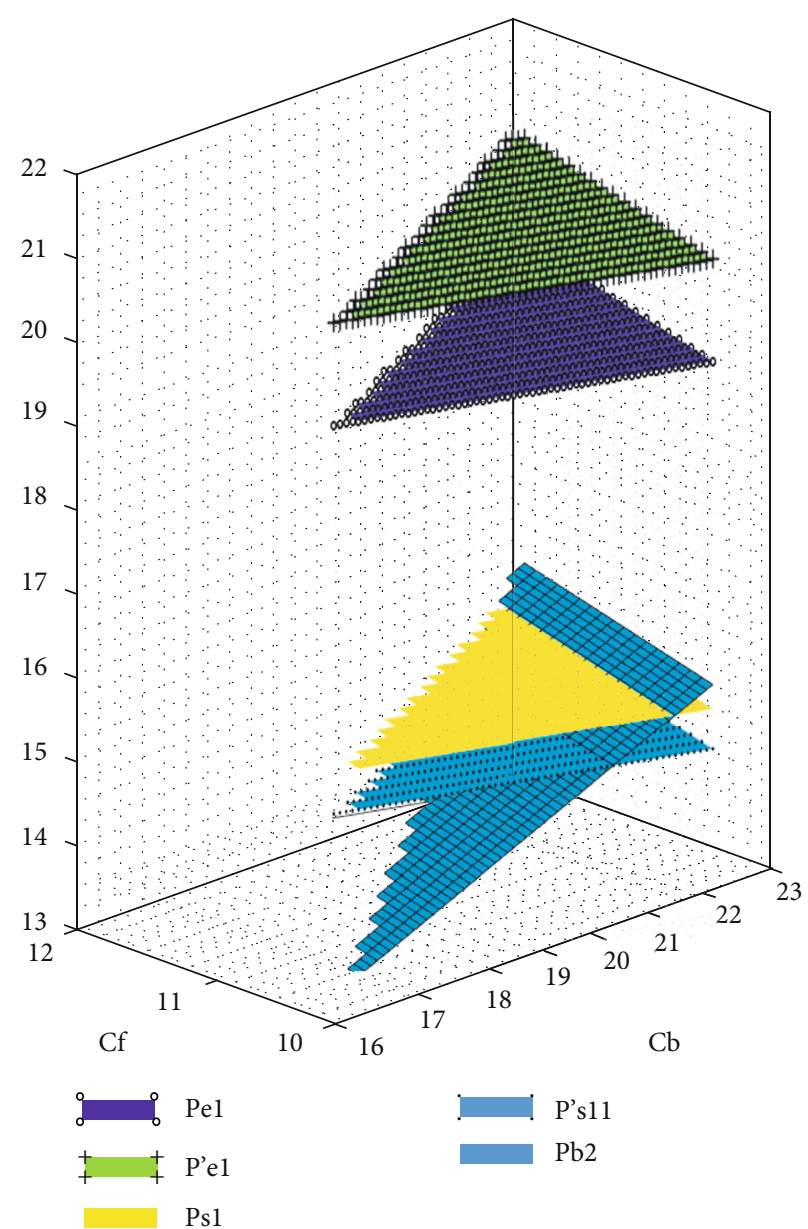

FIgURE 7: Changes in pricing of e-commerce platforms under the joint action of $C_{f}$ and $C_{b}$.

From the perspective of e-commerce platforms, this paper discussed the strategic issues of bilateral business cooperation pricing between e-commerce platforms, banking institutions, and service providers in supply chain finance and discussed the pricing decisions of e-commerce platforms under different bargaining orders. Analyze the influence of partners' bargaining power, cost and incentive factors on pricing decisions, and draw the following conclusions: first, the pricing decisions of e-commerce platforms are related to the efforts of partners, bargaining power and other factors, and e-commerce platforms. The higher the negotiated price, the more helpful it is to strengthen the cooperation between the service provider and the platform; the quotation proposed by the platform to the bank increases with the decrease of the counterpart's ability, and the negotiated price increases. High, the more helpful it is to strengthen the cooperation between the platform and banking institutions. It shows that e-commerce platforms can explore multiplatform pricing cooperation and revenue coordination strategies based on their expected benefits and partner negotiation capabilities. The second conclusion is the pricing decisions of service which providers and banks change with changes in their respective costs. Both parties can proceed from reality and adjust their decisions by 
controlling relevant business costs. It shows the importance of reducing costs and improving risk control capabilities to all parties. With the introduction of incentive mechanisms for partners, under certain conditions, the cost pressure of the other party can be alleviated, playing a role in cooperation incentives and behavioral restraints, indicating that appropriate incentive conditions are considered, such as subsidies for partners' costs or risks. And incentives, constraints on cooperative business processes, etc., will help realize multiplatform mutual profit and promote cooperative alliances. In terms of strategic choice, if the ecommerce platform chooses to negotiate pricing with the bank first, the pricing reward will be higher than the reward it would obtain after negotiating the pricing with the service provider and then negotiating the pricing with the bank; at the same time, the platform can make a decision with reference to the value range and conditions of the partner's cost coefficient.

\section{Conclusion}

The research paper concludes that the realistic for online supply chain financial services, especially those in which ecommerce platforms, banking institutions, and fourthparty logistics service providers participate in cooperation, and coordinate the pricing decisions and interest relationships between e-commerce platforms and partners significance, help to improve the overall cooperation intensity and efficiency, and promote the optimal allocation and integration of upstream and downstream resources. However, this article also has some limitations. It does not consider the risk factors involved in the business. The value and interval uniform distribution of parameters and other ways of cooperation need to be further explored. This is also the direction of follow-up research and will be in future research. Look at the problem with a developmental perspective. Combining the research content, try to put forward the following suggestions for the development of supply chain finance and the cooperation strategy of e-commerce platforms: first, for e-commerce platforms, they should make better use of their unique network technology advantages in bilateral business cooperation and expand customer groups. Strengthen the construction of information platforms, further promote the flow of upstream and downstream information, improve the collection and management of customer enterprise information and credit evaluation, and improve bank credit entrustment services, thereby helping banks reduce transaction risks and improve review efficiency. On the other hand, it will strengthen cooperation with service providers in logistics and product services, and strengthen standardization work such as ecommerce and logistics docking and data sharing, so as to optimize the transportation and circulation efficiency of online products and improve the basic service level of products. Second, for banks, further improve financial services, achieve customer segmentation and precise marketing, reduce the cost of information asymmetry, and improve the efficiency of credit and risk management; for service providers, pay more attention to technology and resource opti- mization. Improve the efficiency of product operation by improving the smart logistics service system and product sales chain. Third, innovate technology and optimize the external environment. Use terminal technology, artificial intelligence, digitization, cloud computing, and other technologies to establish a digital credit system to provide risk control and technical support for operations on the supply chain; at the same time, adhere to the guidance of the government to promote leading enterprises and e-commerce enterprises to drive upstream and downstream small and medium-sized enterprises enterprise development, improve corporate financing efficiency, and provide a beneficial environment for promoting new channels and new development of supply chain finance.

\section{Data Availability}

All data has been included in the manuscript.

\section{Conflicts of Interest}

The authors declare that they have no conflicts of interest.

\section{References}

[1] A. Nagurney, P. Daniele, and S. Shukla, "A supply chain network game theory model of cybersecurity investments with nonlinear budget constraints," Annals of Operations Research, vol. 248, no. 1-2, pp. 405-427, 2017.

[2] Q. Hu, Z. Xu, T. Dinev, and H. Ling, "Does deterrence work in reducing information security policy abuse by employees?," Communications of the ACM, vol. 54, no. 6, pp. 54-60, 2011.

[3] R. W. Johnstone, "Not safe enough: fixing transportation security," Issues in Science and Technology, vol. 23, no. 2, pp. 51-60, 2007.

[4] N. J. Rowan and C. M. Galanakis, "Unlocking challenges and opportunities presented by COVID-19 pandemic for crosscutting disruption in agri-food and green deal innovations: Quo Vadis?," Science of the Total Environment, vol. 748, p. 141362, 2020.

[5] C. Zhao and B. Chen, "China's oil security from the supply chain perspective: a review," Applied Energy, vol. 136, pp. 269-279, 2014.

[6] X. Wang, Y. Wu, L. Liang, and Z. Huang, "Service outsourcing and disaster response methods in a relief supply chain," Annals of Operations Research, vol. 240, no. 2, pp. 471-487, 2016.

[7] H. Song, K. Yu, A. Ganguly, and R. Turson, "Supply chain network, information sharing and SME credit quality," Industrial Management \& Data Systems, vol. 116, no. 4, pp. 740-758, 2016.

[8] M. S. Heng, "Research note: implications of e-commerce for banking and finance," SSRN Electronic Journal, vol. 12, no. 7, pp. 392-401, 2006.

[9] R. S. Bhatti, P. Kumar, and D. Kumar, "Analytical modeling of third party service provider selection in lead logistics provider environments," Journal of Modelling in Management, vol. 5, no. 3, pp. 275-286, 2010.

[10] G.-S. Tang, "Supply chain governance level, bank's perception of the seller and bank credit," in in 2014 International Conference on Management Science \& Engineering 21th Annual Conference Proceedings, pp. 1333-1338, IEEE, 2014. 
[11] E. Francis, J. Blumenstock, and J. Robinson, Digital Credit: A Snapshot of the Current Landscape and Open Research Questions, CEGA White Paper, 2017.

[12] J. Wikner, D. R. Towill, and M. Naim, "Smoothing supply chain dynamics," International Journal of Production Economics, vol. 22, no. 3, pp. 231-248, 1991.

[13] A. Amid, S. Ghodsypour, and C. O'Brien, "A weighted maxmin model for fuzzy multi-objective supplier selection in a supply chain," International Journal of Production Economics, vol. 131, no. 1, pp. 139-145, 2011.

[14] A. V. Iyer and M. E. Bergen, "Quick response in manufacturerretailer channels," Management Science, vol. 43, no. 4, pp. 559570, 1997.

[15] I. Triulzi, F. Di Pasquale, A. Antonel, E. Rossi, and G. Turchetti, "PP155 demand side and supply side of healthcare supply chain," International Journal of Technology Assessment in Health Care, vol. 35, no. S1, pp. 66-67, 2019.

[16] M. E. Ferguson, "When to commit in a serial supply chain with forecast updating," Naval Research Logistics (NRL), vol. 50, no. 8, pp. 917-936, 2003.

[17] F. Mazzetto, R. A. Ortiz-Gutiérrez, D. Manca, and F. Bezzo, "Strategic design of bioethanol supply chains including commodity market dynamics," Industrial \& Engineering Chemistry Research, vol. 52, no. 30, pp. 10305-10316, 2013.

[18] D. Lanier Jr., W. F. Wempe, and Z. G. Zacharia, “Concentrated supply chain membership and financial performance: chainand firm-level perspectives," Journal of Operations Management, vol. 28, no. 1, pp. 1-16, 2010.

[19] M. Du, Q. Chen, J. Xiao, H. Yang, and X. Ma, "Supply chain finance innovation using blockchain," IEEE Transactions on Engineering Management, vol. 67, no. 4, pp. 1045-1058, 2020.

[20] K. N. Qureshi, R. Hussain, and G. Jeon, "A distributed software defined networking model to improve the scalability and quality of services for flexible green energy internet for smart grid systems," Computers Electrical Engineering, vol. 84, article 106634, 2020.

[21] M. Marques, M. F. Da Costa, M. I. D. O. Mayorga, and P. R. C. Pinheiro, "Water environments: anthropogenic pressures and ecosystem changes in the Atlantic drainage basins of Brazil," Environment, vol. 33, no. 1, pp. 68-77, 2004.

[22] J. Manne, C. S. Snively, M. Z. Levy, and M. R. Reich, "Supply chain problems for Chagas disease treatment," The Lancet Infectious Diseases, vol. 12, no. 3, pp. 173-175, 2012.

[23] K. N. Qureshi, O. Kaiwartya, G. Jeon, and F. Piccialli, "Neurocomputing for internet of things: object recognition and detection strategy," Neurocomputing, vol. 8, no. 22, pp. 623-635, 2021.

[24] Y.-W. Kim, S.-H. Han, J.-S. Yi, and S. Chang, "Supply chain cost model for prefabricated building material based on time-driven activity-based costing," Canadian Journal of Civil Engineering, vol. 43, no. 4, pp. 287-293, 2016.

[25] A. Hasan and K. Qureshi, "Internet of things device authentication scheme using hardware serialization," in in 2018 International Conference on Applied and Engineering Mathematics (ICAEM), pp. 109-114, IEEE, 2018.

[26] T.-J. Yang, "Financial performance analysis of e-collaboration supply chain under transportation disruptions," in in 2008 International Symposium on Computer Science and Computational Technology, vol. 2, pp. 435-439, IEEE, 2008.

[27] A. Paz, G. El Boussaidi, and M. Hafedh, "checsdm: a method for ensuring consistency in heterogeneous safety-critical sys- tem design," IEEE Transactions on Software Engineering, vol. 5, no. 23, pp. 226-234, 2020.

[28] A. Filippov and S. Shkirskaya, "Verification of the cell (heterogeneous) model of an ion-exchange membrane and its comparison with the homogeneous model," Colloid Journal, vol. 81, no. 5, pp. 597-606, 2019.

[29] K. Riad and J. Cheng, "Adaptive XACML access policies for heterogeneous distributed IoT environments," Information Sciences, vol. 548, pp. 135-152, 2021.

[30] R. S. Jayne, H. Wu, and R. M. Pollyea, "Geologic $\mathrm{CO}_{2}$ sequestration and permeability uncertainty in a highly heterogeneous reservoir," International Journal of Greenhouse Gas Control, vol. 83, pp. 128-139, 2019.

[31] E. Yang, D.-K. Kang, and C.-H. Youn, "BOA: batch orchestration algorithm for straggler mitigation of distributed DL training in heterogeneous GPU cluster," The Journal of Supercomputing, vol. 76, no. 1, pp. 47-67, 2020.

[32] G. Xie, W. Ma, H. Peng, R. Li, and K. Li, "Price performancedriven hardware cost optimization under functional safety requirement in large-scale heterogeneous distributed embedded systems," IEEE Transactions on Industrial Electronics, vol. 68, no. 5, pp. 4485-4497, 2019.

[33] Y. Yu, Z. Li, D. Zhang, L. Xing, and H. Peng, "Simulation studies of time reversal-based protoacoustic reconstruction for range and dose verification in proton therapy," Medical Physics, vol. 46, no. 8, pp. 3649-3662, 2019. 